This item was submitted to Loughborough's Research Repository by the author.

Items in Figshare are protected by copyright, with all rights reserved, unless otherwise indicated.

\title{
Effect of compression ring elastodynamics behaviour upon blowby and power loss
}

PLEASE CITE THE PUBLISHED VERSION

http://dx.doi.org/10.4271/2014-01-1669

PUBLISHER

(C) SAE

VERSION

VoR (Version of Record)

LICENCE

CC BY-NC-ND 4.0

REPOSITORY RECORD

Baker, Christopher E., Ramin Rahmani, loannis Karagiannis, Stephanos Theodossiades, Homer Rahnejat, and Alan Frendt. 2019. "Effect of Compression Ring Elastodynamics Behaviour Upon Blowby and Power Loss". figshare. https://hdl.handle.net/2134/15883. 


\section{Effect of Compression Ring Elastodynamics Behaviour upon Blowby and Power Loss}

\section{Christopher Baker and Ramin Rahmani}

Loughborough University

\section{loannis Karagiannis}

AVL Powertrain UK Ltd.

\section{Stephanos Theodossiades and Homer Rahnejat}

Loughborough University

\section{Alan Frendt \\ Aston Martin Lagonda}

CITATION: Baker, C., Rahmani, R., Karagiannis, I., Theodossiades, S. et al., "Effect of Compression Ring Elastodynamics Behaviour upon Blowby and Power Loss," SAE Technical Paper 2014-01-1669, 2014, doi:10.4271/2014-01-1669.

Copyright (C) 2014 SAE International

\begin{abstract}
The automotive industry is subject to increasing pressure to reduce the $\mathrm{CO}_{2}$ emissions and improve fuel efficiency in internal combustion engines. Improvements may be achieved in a number of ways. The parasitic losses throughout the engine cycle emanate from friction in all engine contact conjunctions in addition to pumping losses. In particular one main contributory conjunction is the piston ring pack assembly. At low engine speeds, the contribution of friction to the total losses within the engine is increased significantly compared with the thermodynamic losses. Additionally, the sealing capability of the ring is crucial in determining the power output of the engine with any loss of sealing contributing to power loss, as well as blowby. Most reported studies on compression ring-cylinder conjunction do not take into account complex ring in-plane and out-of-plane elastodynamics. Hitherto, there has not been a numerical methodology which integrates tribology of an elastic compression ring, subject to modal behaviour in a coupled solution.
\end{abstract}

This paper discusses the inclusion of transient ring elastodynamics of the top compression ring, interacting with blowby effects within the ring pack. The ring dynamics methodology is briefly highlighted for both in-plane and out-of-plane motions. In addition, a one-dimensional gas flow model that captures blowby behaviour is included. A case study is presented, using measured engine data. Gas flow and frictional losses at various engine speeds are predicted. The effect of gas blowby on the ring's tribological response can be ascertained, as well as the ring's dynamic motion within its retaining groove.

\section{Introduction}

The need for improvements in engine efficiency has become more essential due to the Kyoto Protocol adopted in 1997. The diminishing fossil fuel resources, alongside the $\mathrm{CO}_{2}$ emission levels have encouraged governments to impose financial penalties for non-compliance with prescribed emissions limits. Advances in engine power output and a reduction in emissions are both targets which can be reached by engine design improvements, such as fuel consumption in an efficient manner as possible.

The main modes of energy loss from an internal combustion engine are thermal and parasitic. Thermal losses are principally generated during the process of combustion, as the various components are heated as a by-product of the fuel burning process. Parasitic losses are those due to generated friction between contacting moving parts, or where the movement of a part may not be particularly efficient in generating vehicle motion. At low engine speeds, parasitic losses are proportionally higher with respect to thermal losses as opposed to higher engine speeds. This paper focuses on the piston ring pack, particularly the top compression ring.

The modelling of piston ring elastodynamics originates from studies regarding the modal response of incomplete circular arches. Lamb [1] was one of the first to study this problem, examining the modal response of small curved bars. An approximate solution to out-of-plane vibrations was presented by Brown [2], the results of which fell within an acceptable level of error when compared with experimental results. Love []] described the classical equations of motion for a thin 
incomplete ring, after building on previous work by Mayer [4]. The inextensional vibrations of incomplete rings with small cross sections were discussed by Archer []], with clamped boundary conditions. Modal results were presented, showing both the natural frequencies and mode shapes. Lang [] $]$ presented the full dynamic solution methodology for an incomplete ring, with a variety of boundary conditions considered. The mechanical model by Lang [] $]$ is shown in figure 1.

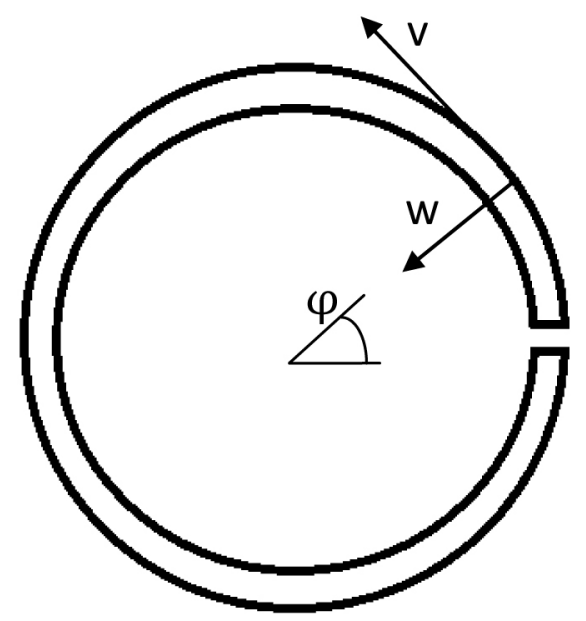

Figure 1. Ring in-plane degrees of freedom [] $]$

The out-of-plane modal solution was presented by Ojalvo[7], who built on the previous work of Archer [5] . Figure 2 depicts a cross section of the mechanical model used by Ojalvo. He stated that the in-plane and out-of-plane equations of motion are decoupled, which allows the equations to be solved independently.

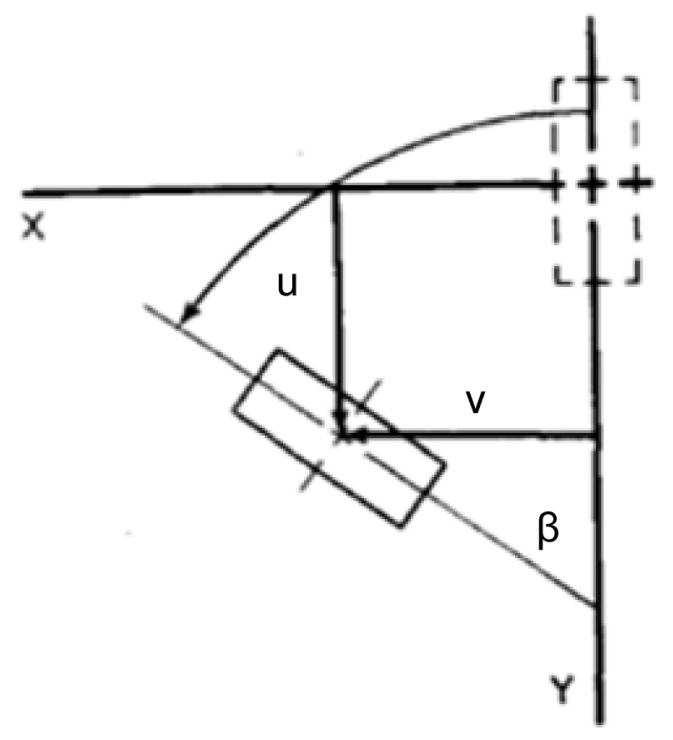

Figure 2. Ring out-of-plane (axial) degrees of freedom [7]

The transient elastodynamics of compression rings are rarely included in a tribological analysis. Whilst ring flutter and blowby is a widely recognised phenomenon, there has been very little research into improving ring tribological models in an effort to capture these phenomena. Therefore, the inclusion of ring dynamics could be a significant step towards understanding blowby and ring motion within the groove.
A tribological study of the piston ring pack can encompass a wide variety of methodologies and backgrounds, due to the complex nature of the conditions encountered throughout the engine cycle. The lubricant properties, entraining velocity and load are all subject to transience, which yield a complex analysis []. According to Taylor []ㅡ, up to 17 influential parameters must be considered when attempting to numerically replicate the ring-liner conjunction, in order to attain results which mirror the 'real life' scenario to an acceptable level of accuracy. This is in part due to the fact that throughout the engine cycle, the top compression ring may pass through all the various regimes of lubrication - boundary, mixed, hydrodynamic and possibly elasto-hydrodynamic (EHL).

Fox et al [10] reported that the lubricant available to the compression ring - cylinder liner conjunction has reduced as restrictions on engine emissions have been enforced on vehicle manufacturers. This reduction in conjunctional gap has led to increased friction of the ring pack from approximately $13 \%$ in the 1980 s, to around $27 \%$ today [11]. A contribution between $13-40 \%$ is generally seen, depending on the engine's running conditions and specifications [11]. Clearly, any reduction in these frictional losses would be beneficial. If all parasitic losses are considered, a 10\% improvement in mechanical losses would reduce fuel consumption by $1.5 \%$, according to Priest and Taylor [12].

Tribological studies of the compression ring have been performed from both a numerical and experimental perspective. Furuhama $[\underline{13}, \underline{14}, \underline{15}]$ undertook a number of experimental and numerical investigations into piston ring tribology. From these reports, further studies on various aspects of the ring-liner conjunction have been carried out. Ma et al [16] and Mishra et al [17] examined ring-bore conformability. Ma concluded that bore distortion may reduce the power loss; however oil consumption would increase as a result. Wing and Saunders [18] fitted inductance transducers to the piston for film thickness measurement. They found the oil-film thickness to be within the range $5-12 \mu \mathrm{m}$. Hamilton and Moore [19] introduced capacity gauges as a method of measuring film thickness and were able to resolve at much lower films, meaning more accurate film measurements were possible when the film thickness was approaching a mixed regime of lubrication. They observed values of $0.4-2.5 \mu \mathrm{m}$, which are more in line with expected values at TDC and BDC especially. Mishra et al [20] used Greenwood and Tripp's [21] method, together with measurements of a real out-of-round cylinder bore, to perform a tribological analysis of the compression ring-bore contact. Reasonable agreement was noted with the experimental data presented by Furuhama and Sasaki [22], as well as previous numerical analysis by Akalin and Newaz [23]. Baker et al [24, 25] presented a methodology, which coupled a verified in-plane dynamic response with the tribological analysis of the piston ring-cylinder liner conjunction.

Regarding blowby, Ting and Mayer [26] considered labyrinth passages made by piston rings for the flow of gas from combustion chamber to the crank case. They assumed the ring end gaps are the only openings for the flow of gas. Ruddy et al [27] modified the previous model to include the frictional losses 
in the flow of gas through piston rings for large bore engines. It was found that for engines with smaller bore sizes, the pressure drop due to the frictional losses is insignificant. Tian et al [28] included the flow of gas through the ring-groove space considering the ring dynamics in the groove, as well as the gas flow through the ring end gap. It was shown that this flow can be described using Reynolds equation for gas flow. Gulwadi [29] also considered gas flow through the end gap, as well as flow through the ring face. The ring face flow was either due to radial lift of the ring face, or existing gaps between the ring face and liner due to the bore distortions and loss of conformability between ring and liner at those areas. This model was devised using the orifice flow model. Further flow through the ring-groove space was also considered, using Reynolds equation. However, the details of the calculation procedure were not given. Three possible gas leakage paths were identified as follows [르, 29]:

\section{The ring end gap}

2. The ring face/liner conjunction (non-conforming areas between rings and the distorted liner)

3. The ring flank and ring groove

Ma et al [30] introduced a thermodynamic model combined with the common gas dynamics model for orifice flow to calculate the blowby gas flow. This method enabled calculation of gas temperature in the inter-ring spaces as well. In all the other models, the gas temperature should be known a priori either by assumption or experimental measurements. This method using the first law of thermodynamics along with gas dynamics and ideal gas law allows calculating gas flow rates, gas pressures and temperatures. However, the paper does not provide details on how the enthalpy of the flowing gas was calculated. Mittler et al [31] developed an analytical tool to demonstrate the effect of axial ring motion and twist on blowby. In-plane ring dynamics were not included in the model, although good agreement between the experimental and analytical results was seen.

This paper is concerned with the coupling of a transient, three-dimensional ring elasto-dynamics model with a gas flow model. The paper focuses on the top compression ring only, although verification of the blowby model is undertaken using a two-ring model. The purpose of this model is to examine the sealing capability of the compression ring throughout the engine cycle, whilst simultaneously predicting the tribological performance.

Figure 3 shows the free body diagram of a section of the top compression ring. The forces acting in the ring's radial direction are captured by the in-plane dynamics methodology; those acting in the axial direction are used in the out-of-plane methodology.

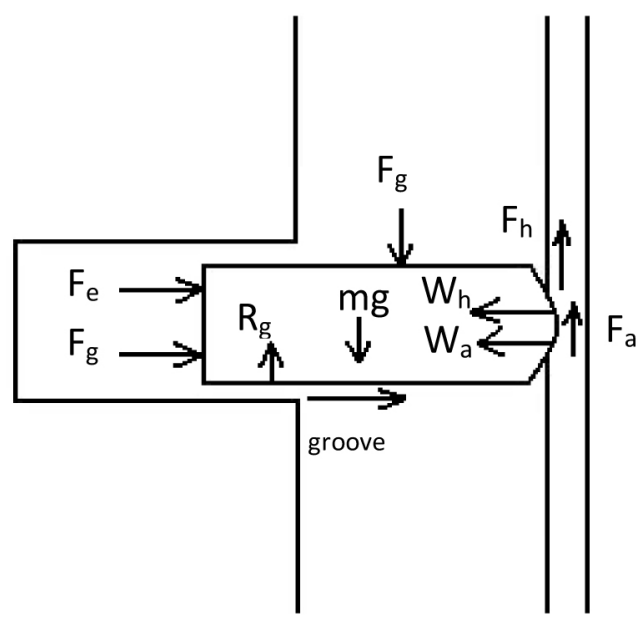

Figure 3. Free body diagram of the compression ring-cylinder liner conjunction.

\section{In-Plane Dynamic Response}

Referring to figure 3 , the in-plane resultant force, ignoring groove friction term $\mathrm{F}_{\text {groove }}$, becomes:

$$
\left(F_{e}+F_{g}\right)-\left(W_{h}+W_{a}\right)=F_{R i n}
$$

The equations of motion which describe the in-plane ring response are derived by Lang []ㅡ:

$$
\begin{gathered}
\frac{\partial^{6} v}{\partial \varphi^{6}}+2 \frac{\partial^{4} v}{\partial \varphi^{4}}+\frac{\partial^{2} v}{\partial \varphi^{2}}+\frac{1}{p \omega_{0}^{2}} \frac{\partial^{4} v}{\partial \varphi^{2} \partial t^{2}}-\frac{1}{p \omega_{0}^{2}} \frac{\partial^{2} v}{\partial t^{2}}= \\
\frac{R^{3}}{E I}\left\{\frac{\partial^{2}}{\partial \varphi^{2}}\left[F_{R i n}(\varphi, t)\right]-\left[F_{T}(\varphi, t)\right]\right\} \\
\frac{\partial^{6} w}{\partial \varphi^{6}}+2 \frac{\partial^{4} w}{\partial \varphi^{4}}+\frac{\partial^{2} w}{\partial \varphi^{2}}+\frac{1}{p \omega_{0}^{2}} \frac{\partial^{4} w}{\partial \varphi^{2} \partial t^{2}}-\frac{1}{p \omega_{0}^{2}} \frac{\partial^{2} w}{\partial t^{2}}= \\
\frac{R^{3}}{E I}\left\{\frac{\partial^{2}}{\partial \varphi^{2}}\left[F_{R i n}(\varphi, t)\right]-\frac{\partial}{\partial \varphi}\left[F_{T}(\varphi, t)\right]\right\}
\end{gathered}
$$

Where $p=\frac{I}{A R^{2}}$ and $\omega_{0}^{2}=\frac{E}{\rho R^{2}} . \mathrm{F}_{\mathrm{T}}$ is the tangential force, which is neglected in this analysis due to the small size of the tangential loads. This is due to piston tilt and bore distortion both not being considered in this study. By solving the eigenvalue problem of equations (2a) and (2b), the natural frequencies and mode shapes can be obtained. This, coupled with the solution to the time-based response of the system (as detailed by Lang [] $]$ and Timoshenko [32]), gives the complete solution of the equations of motion. This allows for calculation of the ring's in-plane modal response (deformed shape), as a function of force profile and time step, $t$. The calculated deformation is returned to the tribological model to update the ring-liner gap shape as:

$$
h(x, y, t)=h_{m}(t)+h_{s}(x, t)+\Delta_{d}(y, t)
$$


In equation (3), $h_{m}(t)$ represents the absolute minimum film thickness for the entire ring at each time step increment, $h_{s}(x)$ is the ring's axial face-width profile (which does not vary, however the angular position with respect to the liner may change due to ring twist), and $\Delta_{d}(y, t)$ is the elastodynamic deflection of the ring.

\section{Out-of-Plane Dynamic Response}

The out-of-plane resultant force equation from figure 3 is shown in equation (4).

$$
\left(m g+F_{g}\right)-\left(F_{h}+F_{a}+R_{g}\right)=F_{\text {Rout }}
$$

The out-of-plane equations of motion take a similar form to the in-plane analysis and are shown in equations (5), in terms of out-of-plane displacement (u) and ring twist $(\beta)$.

$$
\begin{gathered}
\frac{\partial^{4} u}{\partial \varphi^{4}}-R \frac{\partial^{2} \beta}{\partial \varphi^{2}}-k\left(\frac{\partial^{2} u}{\partial \varphi^{2}}-R \frac{\partial^{2} \beta}{\partial \varphi^{2}}\right)=\frac{m R^{4}}{E I_{x}}\left(\frac{\partial^{4} u}{\partial t^{2}}-\frac{F_{R o u t}}{m}\right) \\
\frac{\partial^{2} u}{\partial \varphi^{2}}-R \beta+k\left(\frac{\partial^{2} u}{\partial \varphi^{2}}+R \frac{\partial^{2} \beta}{\partial \varphi^{2}}\right)=\frac{m R^{4}}{E I_{x}}\left(\frac{\Phi}{m}\right)
\end{gathered}
$$

The term $\Phi$ in equation $5 \mathrm{~b}$ represents torsional loading, which is assumed to be diminutive in this analysis. This is assumed as the groove reaction load acting upon the ring acts through the ring's nominal radius. As with the in-plane methodology, the eigenvalue problem is first solved. Equation (6) represents the eigenvalue problem, whilst equation (7) is the set of uncoupled equations.

$$
\begin{gathered}
\frac{\partial^{4} \beta_{n}}{\partial \varphi^{4}}+2 \frac{\partial^{2} \beta_{n}}{\partial \varphi^{2}}+\beta_{n}=-\lambda_{n}\left(\frac{1+k}{R}\right) u_{n} \\
\ddot{\xi}_{n}+\omega_{n}^{2} \xi_{n}=\frac{Q_{n}}{m} f(t)
\end{gathered}
$$

Qn is the term where the excitation force is included in the ring dynamics solution, and takes the form:

$$
Q_{n}=\frac{\int_{0}^{\alpha}\left(F_{R o u t}(\varphi) u_{n}\right) d \varphi}{\int_{0}^{\alpha} u_{n}^{2} d \varphi}
$$

The solution to equations (5) requires solution of equations (6) and (7). The solution takes the form:

$$
u(\varphi, t)=\sum_{n=1}^{\infty} U_{n}(\varphi) \xi_{n}(t)
$$

The transient ring dynamics model is incorporated into the tribological analysis as follows:

- At each crank angle increment, the net force profiles acting upon the ring (equations (1) and (4)) are applied to the ring dynamics model, for the duration of that crank angle step.

- The resultant deformed ring profiles (for in-plane and axial directions) are returned to the tribological analysis, where the circumferential film profiles are updated, along with the localised velocity values

- These updated deflections and velocities are used as the initial conditions for the subsequent crank angle increment, when the dynamics model is next called. Hence the solution can be described as transient, due to the ring's time history being accounted for in the analysis

Seven elastic modes are included in the analysis, both in the ring's plane and in the axial direction. This is because for the engine speeds, loads and geometry assumed, the most extreme ring deflections will be able to be captured by these many modes.

\section{Tribological Analysis of the Top Compression Ring}

The lubricant pressure distribution is calculated using Reynolds Equation:

$$
\frac{\partial}{\partial x}\left[\left(\frac{\rho h^{3}}{6 \eta}\right) \frac{\partial p}{\partial x}\right]+\frac{\partial}{\partial y}\left[\left(\frac{\rho h^{3}}{6 \eta}\right) \frac{\partial p}{\partial y}\right]=\Delta U_{e n t} \frac{\partial}{\partial x}(\rho h)+2 \frac{\partial}{\partial t}(\rho h)
$$

In equation 10, $\Delta U_{\text {ent }}=U_{\text {bore }}-U_{\text {piston }}=-U_{\text {piston }}$ (piston speed) since $U_{\text {bore }}=0$ (stationary bore surface). The lubricant density and viscosity are functions of pressure and temperature. The relationships are given by equations (11) and (12), respectively:

$$
\rho=\rho_{0}\left[1+\frac{0.6 \times 10^{-9}\left(p-p_{0}\right)}{1+1.7 \times 10^{-9}\left(p-p_{0}\right)}\right]\left[1-\beta_{p}\left(\theta-\theta_{0}\right)\right]
$$

$$
\eta=\eta_{0} e^{\alpha_{p} p}
$$

where $\theta$ is the temperature in Kelvin, the subscript 0 denotes ambient conditions and $\alpha_{p}, \beta_{p}$ are constants.

The friction generated within the contact comes from either asperity interaction or lubricant shear $\left(F_{a}\right.$ and $F_{h}$ in equation (4)). The asperity friction was defined by Priest [33], who used Greenwood \& Tripp's [21] asperity load bearing model:

$$
f_{b}=\tau_{0} A_{e}+\xi W_{a}
$$

$T_{0}$ is known as the Eyring shear stress, while $\xi$ is the pressure coefficient for the boundary shear strength in asperities, and $\mathrm{W}_{\mathrm{a}}$ is the asperity load. This coefficient is considered to equal 0.17 for ferrous material. $A_{e}$ is the effective area of the contact, accounting for asperities [21]:

$$
A_{e}=\pi^{2}(\zeta \kappa \sigma)^{2} \sqrt{\frac{\sigma}{\kappa}} E^{\prime} A F_{2}(\lambda)
$$


Further to the boundary friction, viscous friction must also be considered, as shown in equation (15):

$$
f_{v}=\tau\left(A-A_{e}\right)
$$

where $T$ is the viscous shear at each circumferential point and A is the ring's face area. Equation (16) shows the expression for the viscous shear, which varies at each point on the ring:

$$
\tau=\frac{h}{2} \frac{\partial p}{\partial x}+\frac{\eta \Delta U_{e n t}}{h}
$$

As the viscous shear is a function of film thickness, $h$, the value of viscous shear varies both circumferentially and axially.

\section{Gas Flow Model}

A cross-section of the compression ring with the various control volumes is shown in figure 4 . Control volume $A$ is assumed to be at cylinder pressure, whilst control volume $D$ assumes the crankcase pressure.

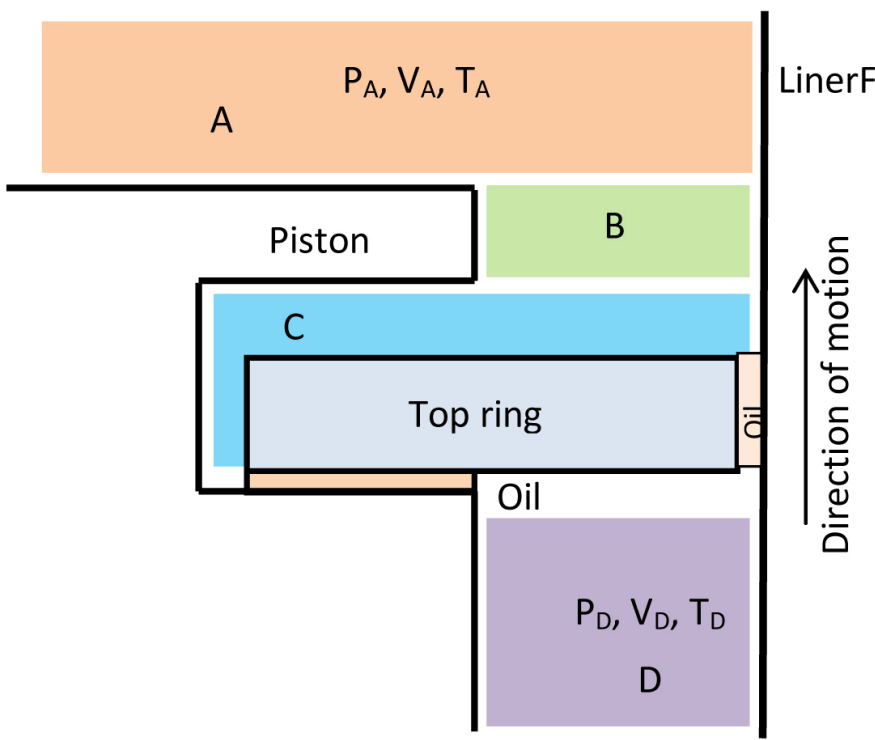

Figure 4. Compression ring cross-section with control volumes for the gas flow model

The gas flow model used in this analysis is a modification of the ones presented by Gulwadi [29] and Ruddy et al [27]. Only the top ring is considered in this study. The mass flow rate from $A$ to $B$ is calculated as follows, using Reynolds equation for the gas, as well as the ideal gas law [29]:

$$
\dot{m}_{1}=\frac{A_{1} h_{1}^{2}}{24 l_{1}} \frac{1}{\eta_{g a s} R T_{B, I}}\left(P_{A}^{2}-P_{B, I}^{2}\right)
$$

where $A_{1}$ is the cross-sectional area for control volume $A, h_{1}$ is the distance between the liner and piston top land, $I_{1}$ is the top land height, $P_{A}$ is the cylinder pressure and $P_{B, I}$ is the initial pressure assumed in control volume $B$. The same methodology is used to calculate the mass flow rate through the other control volumes, although the cross-sectional areas of the control volumes may vary.

The standalone gas flow model was verified against results from Namazian and Heywood [34]. Figure 5 shows the numerical results used to verify the blowby model, showing the mass into, out of and trapped within the ring pack. These results were compared with those presented by Namazian and Heywood [34] in figure 6. Good agreement can be seen between the results. Plots $a, b$ and $c$ refer to the area above the piston, above the top ring and below the top ring respectively.
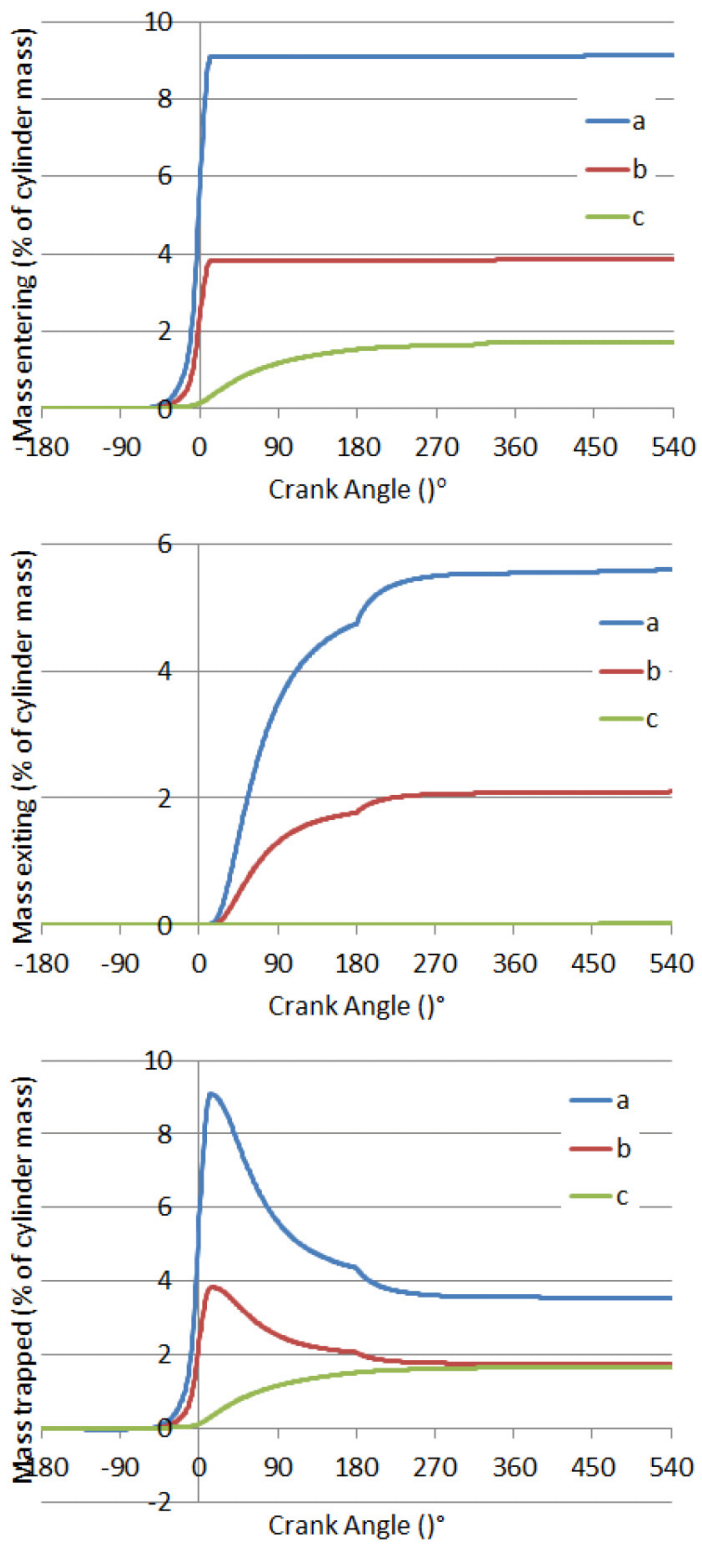

Figure 5. Mass flow results from the standalone gas flow model presented in this paper. Figure shows mass entering, exiting and trapped in the ring pack, at 3 control volumes 


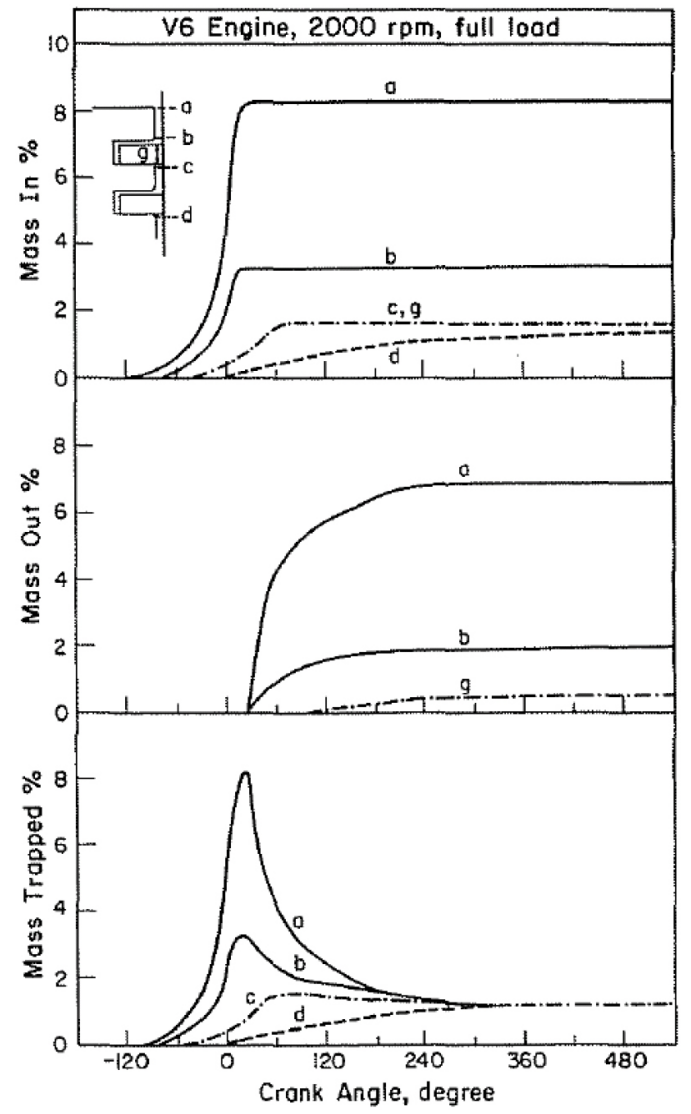

Figure 6. Mass flow results from Namazian \& Heywood [34]

The gas flow model was incorporated in the tribodynamic analysis by utilising the out-of-plane dynamics methodology. Previously, the ring's groove location for the gas flow model was found using a Newtonian type relationship and iterating through the engine cycle to determine the ring's location at each crank angle. However, the need for this iteration is negated when including the out-of-plane transient ring response. The ring's position at each crank angle increment has been determined with the gas mass flow and pressure in each control volume (CV) calculated according to the ring's position. The calculated gas pressure above and behind the ring is then used in the next time step to evaluate the forces acting upon the ring, as well as the boundary conditions when solving Reynolds Equation. The combination of transient ring dynamics and gas flow model into the analysis is a novel approach.

\section{Results and Discussion}

Table 1 shows the compression ring parameters for the numerical analysis. The lubricant properties are highlighted in table 2.

Table 1. Compression ring properties

\begin{tabular}{|l|l|l|}
\hline Parameter & Value & Unit \\
\hline Ring thickness & 3.5 & $\mathrm{~mm}$ \\
\hline Ring axial height & 1.151 & $\mathrm{~mm}$ \\
\hline Ring neutral radius (fitted) & 42.75 & $\mathrm{~mm}$ \\
\hline Elasticity modulus & 203 & $\mathrm{GPa}$ \\
\hline
\end{tabular}

Table 2. Lubricant properties

\begin{tabular}{|l|l|l|}
\hline Parameter & Value & Unit \\
\hline $\begin{array}{l}\text { Lubricant Kinematic } \\
\text { Viscosity }\end{array}$ & $8.5 @ 100^{\circ} \mathrm{C}$ & $\mathrm{mm}^{2} / \mathrm{s}$ \\
\hline Lubricant Density & $0.864 @ 15^{\circ} \mathrm{C}$ & $\mathrm{g} / \mathrm{ml}$ \\
\hline Lubricant temperature & 80 & ${ }^{\circ} \mathrm{C}$ \\
\hline Pressure-viscosity coefficient & $\underline{2^{*} 10^{-8}}$ & $\underline{\mathrm{m}^{2} / \mathrm{N}}$ \\
\hline
\end{tabular}

The cylinder gas pressure profiles were provided by industrial collaborators with a typical pressure profile shown in figure 7 . The peak pressure loading conditions for various engine speeds are shown in table 3.

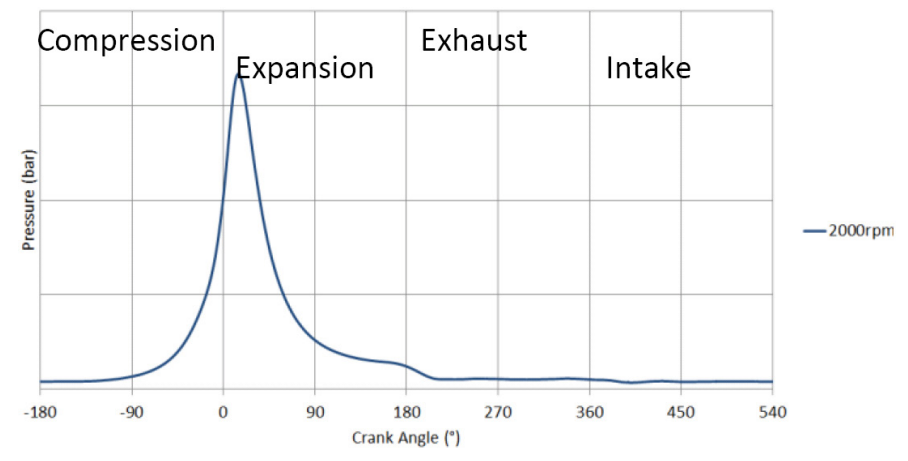

Figure 7. Gas pressure profile. Engine speed $=2000 \mathrm{rpm}, \mathrm{load}=82.5 \%$

Table 3. Peak pressure loading conditions

\begin{tabular}{|l|c|}
\hline $\begin{array}{c}\text { Engine Speed } \\
(\mathrm{rpm})\end{array}$ & Load condition \\
\hline $1000 \mathrm{rpm}$ & $82.5 \%$ \\
\hline $1500 \mathrm{rpm}$ & $82.5 \%$ \\
\hline $2000 \mathrm{rpm}$ & $82.5 \%$ \\
\hline $2500 \mathrm{rpm}$ & $82.5 \%$ \\
\hline $3000 \mathrm{rpm}$ & $82.5 \%$ \\
\hline $3500 \mathrm{rpm}$ & $82.5 \%$ \\
\hline $4000 \mathrm{rpm}$ & $82.5 \%$ \\
\hline
\end{tabular}

Figure 8 shows the minimum film thickness at varying lower engine speeds. Each crank angle interval is divided in 150 timesteps to ensure that no instability occurs, and allow the code to run through the crank angle ranges of high speed and pressure. The expected trend is seen, with higher engine speeds yielding larger film thicknesses throughout the engine cycle. Figures 9 and 10 demonstrate the impact of including 3D ring dynamics, with the circumferential pressure plotted alongside the ring's film thickness profile, with snapshots presented at $0^{\circ}$ and $15^{\circ}$ (point of maximum pressure). It is seen that, even for the very small differences between "minimum" and "maximum" film thickness, the pressure can differ by several MPa between one side of the ring and the other. The small film thickness difference circumferentially is a result of assuming a cylindrical bore, as well as no piston tilt. Since bore out-of-roundness is likely to be tens of $\mu \mathrm{m}$ in magnitude, this would affect the model significantly. Figure 9a shows the $1^{\text {st }}$ elastic mode is dominant in the response, whilst figure $9 \mathrm{~b}$ shows the influence of the $2^{\text {nd }}$ and third elastic modes. 


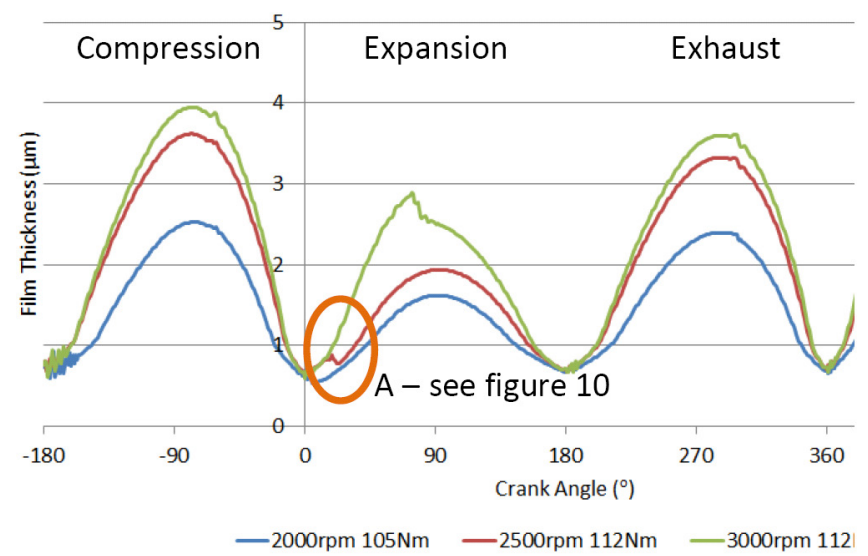

Figure 8. Minimum film thickness at varying engine speeds

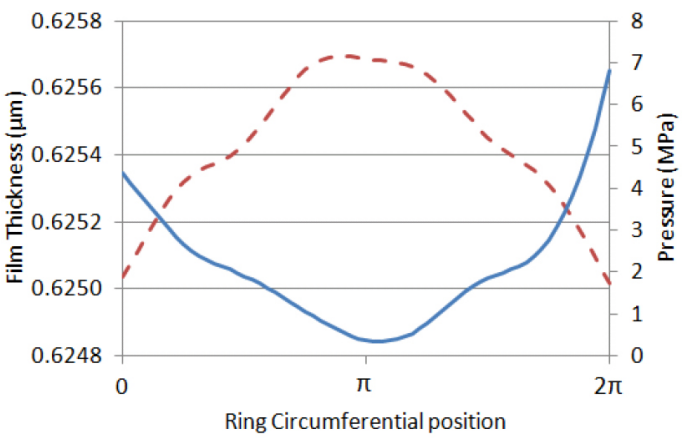

- - Film Thickness —Viscous Pressure

(a)

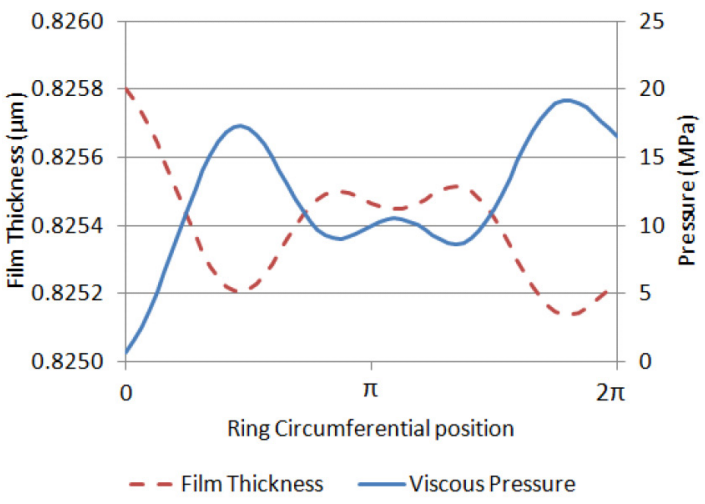

(b)

Figure 9. Circumferential film thickness and viscous pressure profiles, at (a) $0^{\circ}$ and (b) the point of maximum pressure

Figure 10 shows the corresponding ring position within the groove, whilst figure 11 shows the net gas mass flow through the ring pack. Figure 10 is a result of plotting each $3 D$ ring deformation profile (see inset), to allow the overall trend to be observed. If no gas pressure was seen, the ring motion would be dictated by the piston's axial velocity. However in the expansion stroke, the gas pressure is sufficient to act against the piston's inertial force, which pushes the ring away from the groove. This is why the 'fluttering' effect is seen in the expansion stroke. The ring's position is seen to affect the film thickness, which in turn will alter the friction generated within the contact. When the ring is forced against the lower groove face through the power stroke (particularly at 3000rpm) the minimum film thickness is decreased because a greater proportion of the combustion pressure acts behind the ring. A lower engine speed results in the ring being forced to the bottom groove face earlier in the engine cycle.

The areas around the combustion point (between crank angles of $-90^{\circ}$ and $90^{\circ}$ ) see the ring moving rapidly within the groove, particularly at high 3000rpm. This behaviour could be an indicator of ring flutter. The flutter occurs at the same crank angle position, where a higher mass flow rate is observed. The full 3D ring deformation can be seen in the inset of figure 10, and is obtained by solving the ring elasto-dynamic equations detailed in this paper. The inset in figure 10 demonstrates that elastic deformation of the ring in the axial direction occurs. The deflections shown are of the magnitude of tens of $\mu \mathrm{m}$. For this particular snapshot, the $3^{\text {rd }}$ elastic mode dominates the ring's transient response.

The type of motion seen in figure 10 has also been reported by Takiguchi et al [35], although for different loading conditions and the secondary compression ring.

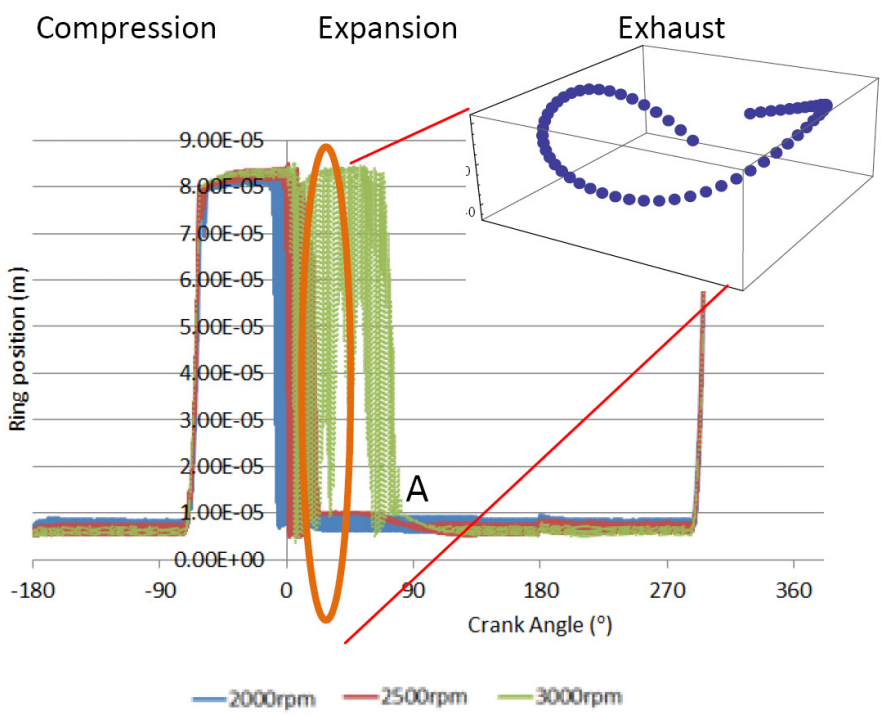

Figure 10. Groove position at varying engine speeds

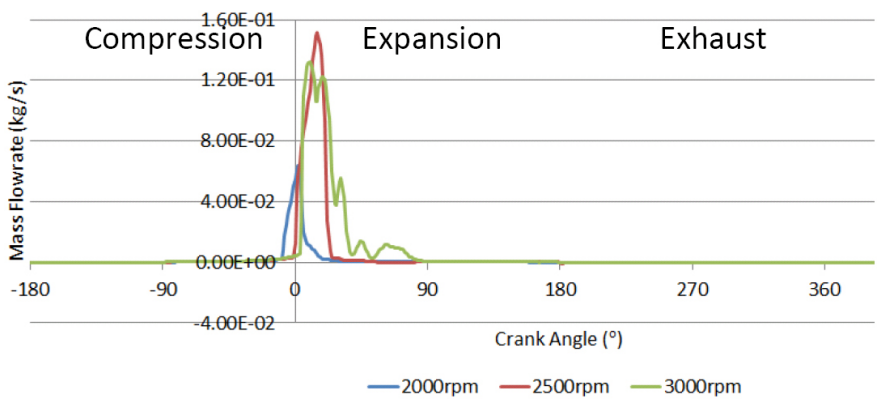

Figure 11. Gas flow rate at varying engine speeds

The power loss at these engine speeds is shown in figure 12. It can be seen that the highest peak power loss actually occurs at the lowest engine speed for this study. This is because the film thickness is thinner for lower engine speeds, so the asperity interaction is more severe when the engine speed is lower. At 2500rpm the ring is forced away from the top groove face, which has been demonstrated in figure 10 (denoted by area $\mathrm{A}$ ). This causes more of the cylinder pressure to act upon 
the back of the ring, which reduces the film thickness between the ring and the liner. The result is the sharp increase in power loss highlighted in figure 12 , at area $\mathrm{A}$. The numerical model highlights the importance of gas pressure behind the ring, as well as the significance of keeping control of the compression ring's motion. For areas such as the mid-stroke, where hydrodynamic lubrication is prevalent, the higher engine speeds yield greater power loss, as expected. Asperity interactions also occur at the other top and bottom dead centre points. This causes the small peaks either side of the other dead centres to occur. Integrating the power loss over the whole engine cycle gives the energy loss values shown in figure 13.

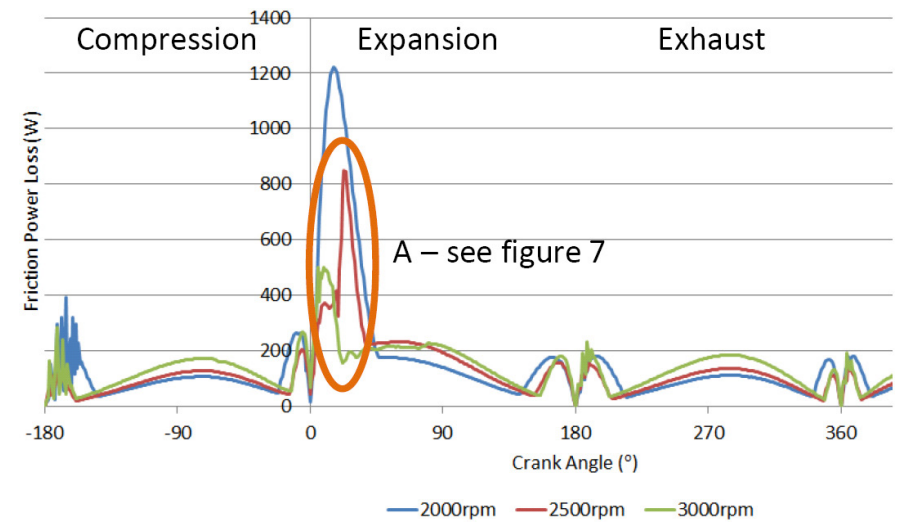

Figure 12. Frictional power loss at various engine speeds

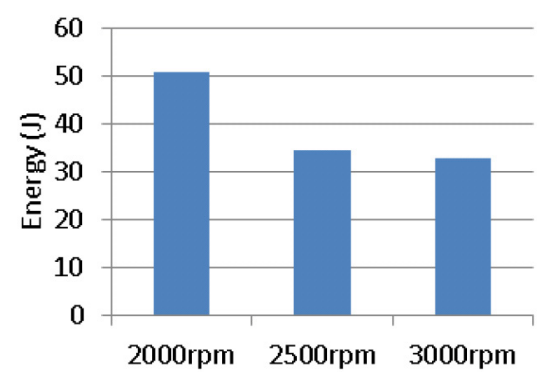

Figure 13. Energy lost per cycle

\section{Conclusions}

This study presented a novel approach to include ring dynamics into the tribological analysis of the top compression ring. The method by which this analysis is coupled is also highlighted. A verified gas flow model was then included into the tribodynamic compression ring model, allowing for gas blowby to be predicted using the ring's elastodynamics throughout the engine cycle. Results from this study showed the ring motion within the groove, indicating that elastic deformation occurs and potential occurrences of ring flutter and blowby. The effect of the change in pressure behind the ring was also demonstrated, with film thickness and power loss results shown. The presented results demonstrate the behaviour of the ring within the groove and the effect that this motion has on the tribological performance of the system. This is an analysis which has not been previously presented, demonstrating a novel approach to the optimisation of compression ring behaviour.

\section{Acknowledgments}

The authors wish to express their gratitude to Engineering and Physical Sciences Research Council (EPSRC) for the funding extended to the Encyclopaedic Program Grant (www. Encyclopaedic.org), under which this research is carried out in collaboration with a consortium of industry and academic institutions. In particular, the authors acknowledge the technical support of Aston Martin Lagonda.

\section{References}

1. Lamb, H., "On the Flexure and the Vibrations of a Curved Bar." Proceedings of the London Mathematical Society 1.1 (1887): 365-377.

2. Brown, Fred H. "Lateral vibration of ring-shaped frames." Journal of the Franklin Institute 218.1 (1934): 41-48.

3. Love, A. E. H. A treatise on mathematical theory of elasticity, 1944 (Dover, New York).

4. Mayer, R. Uber Elastizitat und Stabilitat des geschlossenen und offenen Kreisbogens. Zeitschr.f.angewandte Math.u.Phys., 1921, Bd.61, 246-322.

5. Archer, Robert R. "Small vibrations of thin incomplete circular rings." International Journal of Mechanical Sciences 1.1 (1960): 45-56.

6. Lang, T. E. "Vibration of thin circular rings." Jet Propulsion Laboratory Technical Report 32-261 (1962).

7. Ojalvo, I. U. "Coupled twist-bending vibrations of incomplete elastic rings." International Journal of Mechanical Sciences 4.1 (1962): 53-72.

8. Tung, Simona C., and McMillan Michael L. "Automotive tribology overview of current advances and challenges for the future." Tribology International 37.7 (2004): 517-536.

9. Taylor, C. M. "Automobile engine tribology-design considerations for efficiency and durability." Wear 221.1 (1998): 1-8.

10. Fox, M. F., Jones, C.J., Picken, D. J., and Stow, C. G., "The "limits of lubrication" concept applied to the piston ring zone lubrication of modern engines." Tribology Letters 3.1 (1997): 99-106.

11. Richardson, D. E. "Review of power cylinder friction for diesel engines." Journal of engineering for gas turbines and power 122.4 (2000): 506-519.

12. Priest, M., and Taylor C. M.. "Automobile engine tribologyapproaching the surface." Wear 241, no. 2 (2000): 193-203.

13. Furuhama, S., "A dynamic theory of piston-ring lubrication: $1^{\text {st }}$ report, calculation", Bulletin of JSME, 2(7), 423-428 (1959)

14. Furuhama, S., "A dynamic theory of piston-ring lubrication: 2st report, experiment", Bulletin of JSME, 3(10), 291-297 (1960)

15. Furuhama, S., "A dynamic theory of piston-ring lubrication: 3rd report, measurement of oil film thickness", Bulletin of JSME, 4(16), 744-752 (1961)

16. Ma, M. T., Sherrington, I. and Smith., E. H., "Analysis of lubrication and friction for a complete piston-ring pack with an improved oil availability model: Part 1: Circumferentially 
uniform film." Proceedings of the Institution of Mechanical Engineers, Part J: Journal of Engineering Tribology 211.1 (1997): 1-15.

17. Mishra, P. C., Balakrishnan, S. and Rahnejat, H., "Tribology of compression ring-to-cylinder contact at reversal", Proceedings of the Institution of Mechanical Engineers, Part J: Journal of Engineering Tribology 222, no. 7 (2008): 815-826.

18. Wing, R. D., and Saunders Owen. "Oil film temperature and thickness measurements on the piston rings of a diesel engine." Proceedings of the Institution of Mechanical Engineers 186.1 (1972): 1-9.

19. Hamilton, G. M., and Moore S. L.. "First Paper: Measurement of the Oil-Film Thickness between the Piston Rings and Liner of a Small Diesel Engine," Proceedings of the Institution of Mechanical Engineers 188.1 (1974): 253261.

20. Mishra, P. C., Rahnejat, H. and King P. D., "Tribology of the ring-bore conjunction subject to a mixed regime of lubrication." Proceedings of the Institution of Mechanical Engineers, Part C: Journal of Mechanical Engineering Science 223.4 (2009): 987-998.

21. Greenwood, J. A., and Tripp J. H.. "The contact of two nominally flat rough surfaces." Proceedings of the Institution of Mechanical Engineers 185.1 (1970): 625-633.

22. Furuhama, S. and Sasaki, S., "New Device for the Measurement of Piston Frictional Forces in Small Engines," SAE Technical Paper 831284, 1983, doi:10.4271/831284.

23. Akalin, Ozgen, and Newaz Golam M. "Piston ring cylinder bore friction modeling in mixed lubrication regime: part I-analytical results." Journal of tribology 123 (2001): 211.

24. Baker, C. E., Theodossiades, S., Rahnejat, H., and Fitzsimons, B., "Influence of In-Plane Dynamics of Thin Compression Rings on Friction in Internal Combustion Engines." ASME Journal of Engineering for Gas Turbines and Power 134 (2012): 092801.

25. Baker, C. E., Theodossiades, S. and Rahnejat, H., "Friction under transient mixed regime of lubrication in conjunction of an elastic ring within a real cylinder", Proc. ASME ICED Spring Tech. Conference, ICES2012-81045, 6-9 May (2012)

26. Ting, L. L., and Mayer J. E. Jr. "Piston ring lubrication and cylinder bore wear analysis, Part I-Theory." Journal of Lubrication Technology 96 (1974): 305.

27. Ruddy, B. L., Dowson, D., and Economou P. N. "A theoretical analysis of the twin-land type of oil control piston ring." Journal of Mechanical Engineering Science 23.2 (1981): 51-62.

28. Tian, T., Noordzij, L., Wong, V. W., and Heywood, J. B., "Modeling piston-ring dynamics, blowby, and ring-twist effects." Journal of engineering for gas turbines and power 120.4 (1998): 843-854.

29. Gulwadi, Sanjay D. "Analysis of tribological performance of a piston ring pack", Tribology transactions 43.2 (2000): 151162.

30. Ma, Zheng, Henein Naeim A., and Bryzik, W., "A model for wear and friction in cylinder liners and piston rings",
Tribology transactions 49.3 (2006): 315-327.

31. Mittler, R., Mierbach, A., \& Richardson, D, "Understanding the fundamentals of piston ring axial motion and twist and the effects on blow-by", ASME Conference Proceedings (Vol. 2009, No. 43406, (2009): 721-35).

32. Timoshenko, S., and Goodier, J. N., 1951, Theory of Elasticity, 2nd ed., McGraw-Hill, New York.

33. Priest, M., and Taylor C. M.. "Automobile engine tribologyapproaching the surface." Wear 241, no. 2 (2000): 193-203.

34. Namazian, M. and Heywood, J., "Flow in the PistonCylinder-Ring Crevices of a Spark-Ignition Engine: Effect on Hydrocarbon Emissions, Efficiency and Power," SAE Technical Paper $\underline{820088}$, 1982, doi:10.4271/820088.

35. Takiguchi, M., Sasaki, R., Takahashi, I., Ishibashi, F. et al., "Oil Film Thickness Measurement and Analysis of a Three Ring Pack in an Operating Diesel Engine," SAE Technical Paper 2000-01-1787, 2000, doi:10.4271/2000-01-1787.

36. Baker, C., Rahnejat, H., Rahmani PhD, R., and Theodossiades, S., "Analytical Evaluation of Fitted Piston Compression Ring: Modal Behaviour and Frictional Assessment," SAE Technical Paper 2011-01-1535, 2011, doi:10.4271/2011-01-1535.

37. Baker, C. E., Rahmani, R., Theodossiades, S., Rahnejat, $\mathrm{H}$., and Fitzsimons, B., "Thermo- Elastohydrodynamics of a Rough Piston Compression Ring-to-Cylinder Bore Conjunction," Proc. STLE 66th Annual Conference, Atlanta, GA, 15-19 May (2011).

\section{Definitions}

$A_{a}$ - Asperity contact area

$\boldsymbol{A}$ - Nominal contact area of the ring's face-width

$C_{n 1}, C_{n 2}$ - Time response constants

$E$ - Young's modulus of elasticity

$\boldsymbol{F}_{\mathrm{e}}$ - Ring tension

$\boldsymbol{F}_{\boldsymbol{g}}$ - Applied Gas force

$\boldsymbol{F}_{\text {groove }}$ - Groove friction

$\boldsymbol{F}_{\boldsymbol{h}}$ - Lubricant friction force

$F_{\text {Rin }}$ - Net (residual) radial force

$F_{\text {Rout }}$ - Net (residual) axial force

$F_{T}$ - Tangential shear force

$\boldsymbol{F}_{5 / 2}$ - Greenwood and Tripp statistical function

$\boldsymbol{h}$ - Film thickness

$\boldsymbol{h}_{\mathbf{0}}$ - Minimum film thickness

$I$ - Second area moment of inertia of the ring cross-section

$\boldsymbol{m}$ - Ring mass per unit length

p - Pressure

$Q_{n}$ - General forcing function

$\boldsymbol{R}$ - Ring nominal radius

$\boldsymbol{t}$ - Time

$\boldsymbol{U}_{\text {ent }}$ - Speed of entraining motion

$\boldsymbol{U}$ - Out of plane modal response

$\boldsymbol{u}$ - Out of plane displacement 
$\boldsymbol{V}$ - Tangential modal response

$\boldsymbol{v}$ - Tangential displacement

$\boldsymbol{W}$ - Radial modal response

$W_{a}$ - Asperity load share

$\boldsymbol{W}_{\boldsymbol{h}}$ - Lubricant load share

$\boldsymbol{\alpha}$ - Incomplete Ring subtended angle

$\boldsymbol{\beta}$ - Ring twist

$\Delta$ - Global deformation of ring/liner

$\delta$ - Local deformation

$\zeta$ - Asperity distribution per unit area

$\boldsymbol{\eta}$ - Lubricant viscosity

$\boldsymbol{\eta}_{0}$ - Ambient lubricant viscosity

$\boldsymbol{K}$ - Average asperity tip radius

$\boldsymbol{\pi}-\mathrm{Pi}$

$\boldsymbol{\rho}$ - Lubricant density

$\boldsymbol{T}_{0}$ - Eyring shear stress of the lubricant

$\boldsymbol{\omega}_{\boldsymbol{n}}$ - Natural frequency

\section{Abbreviations}

CV - Control Volume

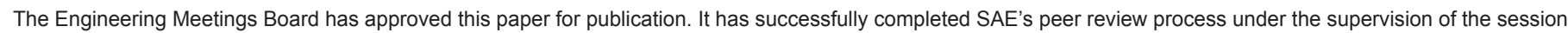
organizer. The process requires a minimum of three (3) reviews by industry experts.

All rights reserved. No part of this publication may be reproduced, stored in a retrieval system, or transmitted, in any form or by any means, electronic, mechanical, photocopying, recording, or otherwise, without the prior written permission of SAE International.

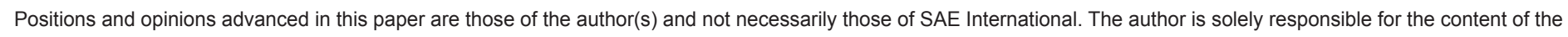
paper.

ISSN 0148-7191

http://papers.sae.org/2014-01-1669 